\title{
CORRECTION
}

\section{Correction: Association of inflammation with depression and anxiety: evidence for symptom-specificity and potential causality from UK Biobank and NESDA cohorts}

Yuri Milaneschi (iD), Nils Kappelmann, Zheng Ye, Femke Lamers (D), Sylvain Moser, Peter B. Jones (iD, Stephen Burgess (iD), Brenda W. J. H. Penninx and Golam M. Khandaker (iD

(c) The Author(s), under exclusive licence to Springer Nature Limited 2021

Molecular Psychiatry (2022) 27:1856; https://doi.org/10.1038/s41380-021-01388-4

Correction to: Mol Psychiatry https://doi.org/10.1038/s41380-02101188-w, Published online 16 June 2021

In this article ref. 7 was incorrect and should have been Mac Giollabhui N, Ng TH, Ellman LM, et al. The longitudinal associations of inflammatory biomarkers and depression revisited: systematic review, meta-analysis, and meta-regression. Mol Psychiatry. 2021;26:3302-3314.

The original article has been corrected. 